can lead to poor coping strategies and the ability to process and come to terms with death and dying. The Samaritans service at the prison reported that previously bereavement was consistently among the top three presenting issues of inmates, since the service began this is no longer cited as a reason for contacting their service.

Conclusions The need was identified to support a group of people who rarely engage with talking therapies or hospice care. By creating the bereavement service, we have made a measurable difference to the lives of inmates. We intend to use the learning from this project to develop services for other hard to reach groups.

\section{0-4 REACHING THOSE WHO WOULD NOT ACCESS HOSPICE CARE IN THE COMMUNITY - UNIVERSITY}

Tracy Tuffs. St Barnabas Hospice, Lincoln, UK

\subsection{6/bmjspcare-2019-HUKNC.4}

Background Having developed the service in the prison we decided to look at other services in Lincolnshire and who they are supporting to be able to identify any other groups of people who do not engage with hospice care or bereavement support.

Aim To develop a service supporting teenagers who have been affected by bereavement. We know that this is a group where there is little support available due to scoping the availability of services in the county and the stigma of talking about bereavement and feelings which still remains which we identified through our scoping conversations.

Methods We had conversations with local University and colleges about how they support students through bereavement and the impact this can have on their education. This identified a lack of support other than some pastoral care with mentors in the school setting.

Results We now have a bereavement counsellor based in the local University, and two colleges around the county. We have had very positive feedback about the impact the service has had on the wellbeing of the students. The services now have a waiting list for students requesting support.

Conclusion The evidence in the growth of the service highlights the need to be supporting people more in the community rather than expecting them to reach out to us for support. This raises the profile of hospice care and the services which can be offered.

\section{Parallel Session 2: Informing Service Development}

\section{0-5 FINDINGS FROM THE FIRST ROUND OF THE NATIONAL AUDIT OF CARE AT THE END OF LIFE (NACEL)}

${ }^{1}$ Debbie Hibbert, ${ }^{1}$ Claire Holditch, ${ }^{2}$ Suzanne Kite, ${ }^{2}$ Elizabeth Rees. ${ }^{1}$ NHS Benchmarking Network, Manchester, UK; ${ }^{2}$ Leeds Teaching Hospitals NHS Trust, Leeds, UK

\subsection{6/bmjspcare-2019-HUKNC.5}

NACEL is a national comparative audit of the quality and outcomes of care experienced by the dying person and those important to them during the last admission leading to death in acute, community hospitals and mental health inpatient providers in England and Wales.

The audit, first undertaken during 2018/19, comprised:

- an Organisational Level Audit covering trusts (in England) and Health Boards (in Wales);

- a Case Note Review completed by acute and community providers only, reviewing all deaths in April 2018 (acute providers) or deaths in April - June 2018 (community providers); and

- a Quality Survey completed online, or by telephone, by the bereaved person.

Data was collected between June and October 2018. 206 trusts in England and eight Welsh organisations took part in at least one element of the audit $97 \%$ of eligible organisations). A total of 11,034 case note reviews were included.

Key findings included the following Documentation that a person may die imminently was high. For half of patients, imminent death was recognised less than one and a half days before they died, leaving a limited amount of time to discuss and implement an individual plan of care.

People's experience of care was good, excellent or outstanding in most cases (80\%) as reported by the Quality Survey. However, $20 \%$ felt that there was scope to improve the quality of care and sensitive communication with both the patient and the family/others.

Governance of end of life care was strong.

Improvement is required in the documentation of an individual plan of care (documented evidence of a plan for $62 \%$ of people who died). Similarly, for one third of people who died, a discussion about the plan of care, and discussions about medication, hydration and nutrition had not been recorded.

The second round of NACEL is running in 2018/19.

\section{0-6 CREATING A COMMUNITY OF OUTSTANDING PRACTICE: WE'RE STILL STANDING BETTER THAN WE'VE EVER BEEN}

Linda Prendergast, Louise Pickford. Mountbatten, Isle of Wight

\subsection{6/bmjspcare-2019-HUKNC.6}

18 months on: background The Island Better Care Programme commenced in January 2018 to support the local care sector to improve Care Quality Commission (CQC) inspection ratings against a background of ratings of 'inadequate' or 'requires improvement'. Delivered by this hospice following an Outstanding CQC inspection with funds from the Local Authority cascaded down from Central Government Better Care Fund.

Aim To provide and share support and tools to evidence good and outstanding care against the CQC key lines of enquiry inspection document. To streamline systems and form networks amongst the groups which may ultimately lead to consistency and ongoing support in the sector where there would have previously been competition for business.

Method A five-day classroom programme and support visits are available to the Proprietors, Managers and Deputies from local Care Providers. A programme of support to approx. 120 care providers: four cohorts per year over a three-year project length. 
Results End of year 1 showed a 68\% improvement to Good out of those who had attended the training. Working together to share ideas to improve quality - 'a really good initiative' CQC Area Manager; 'It has inspired and raised my confidence to pursue an outstanding rating. It is bespoke to the care industry and a brilliant opportunity with the benefit of networking and sharing ideas' Registered Manager, Residential Home.

Conclusion 'Highly innovative in its approach which is helping to transform the people we serve by fully engaging front line colleagues' Director of Adult Social Care. We now need to consider sustainability. With funding streams limited there is a commitment from the Local Authority and Clinical Commissioning Group to continue to find ways of ensuring this programme continues beyond December 2020 to ensure the standards of care provision continue to rise with good evidence provided through the five key lines of enquiry documentation.

\section{0-7 PREPARING THE WAY: EVALUATING SUPPORT FOR CHILDREN BEFORE THE DEATH OF A PARENT OR SIBLING}

Alison Penny. Childhood Bereavement Network, London, UK

\subsection{6/bmjspcare-2019-HUKNC.7}

This presentation will introduce the Serious Illness in the Family Service Questionnaires: a new suite of tools for evaluating support for children and young people who are facing the death of someone important in their lives.

Around 24,000 parents die each year, leaving children under 18 (Childhood Bereavement Network, 2016), with 60$75 \%$ of these deaths being expected (End of Life Care Intelligence Network, 2011). Over 10,000 babies, children and young people under 25 die each year, many leaving siblings (Child Bereavement UK, 2017).

The death of a close family member is associated with a range of poor outcomes for children and young people both in the short and medium term and into adulthood, including early mortality, mental and physical health problems and disrupted education (Penny \& Stubbs, 2015). For children bereaved of a parent through cancer, the time before the death is particularly stressful (Siegel et al., 1992). Over the last three decades, a range of services have developed across the UK to respond to bereaved children's experiences and needs (Rolls \& Payne 2003; Rolls \& Payne 2004; Penny, 2011). An increasing number of services - including many hospices - are also offering support to children before a death, where this is possible.

There are considerable challenges to evaluating this type of support. This presentation will share findings from a project that:

- reviewed the areas of concern to families and practitioners about children's needs before a death in the family;

- scoped interventions and built consensus on the aims of support services in the UK;

- reviewed current quantitative measures being used in evaluations in research and practice;

- identified key challenges to evaluating these interventions;

- developed a suite of self- and parent-reported measures to capture changes towards outcomes across hospices and other services working with children facing the death of someone important.
$0-8$

THE DONOR EXPERIENCE: VALUE CREATION AND THE ROLE OF THE DONOR IN SUPPORTER-LED FUNDRAISING

${ }^{1}$ Katie Mitchell, ${ }^{2}$ Anna Ackfeldt. ${ }^{1} J o h n$ Taylor Hospice, Birmingham, UK; ${ }^{2}$ Aston University, Birmingham, UK

\subsection{6/bmjspcare-2019-HUKNC.8}

Background In 2015, a series of scandals exposed aggressive fundraising practices by charities that had caused distress to donors. In contrast, business has understood that the customer experience is vital to their success (Bitner \& Brown, 2008; Lusch, Vargo \& O’Brien, 2007; Martin, 1999). Services marketing theory describes the role of the customer in 'co-creating' their experience to increase customer satisfaction (Grönroos, 1994). Fundraisers now recognise that how donors feel about their experience of fundraising is crucial. Community fundraising is driven by donors who organise and deliver their own fundraising events and experiences. But there is a gap in our knowledge about the role donors play in creating their own experience and the effect on donor satisfaction.

Aim To examine whether academic models derived from services marketing literature can be applied to community and supporter-led fundraising to improve the donor experience. In particular, we examine the concept of value and the role of the donor in value creation.

Methods A literature review was conducted which highlighted the limited research available. Consequently, an exploratory approach was adopted. Empirical primary data was captured through a series of interviews at case study organisations. Three case studies were identified within a specific typology of organisation: hospice charities that fundraise using similar techniques within their local communities.

Results The concept of value-in-use described by Grönroos (1994) and the role of the donor as an independent creator of value in the customer sphere (Grönroos \& Voima, 2013) was supported by the research and can be applied to the donor experience.

Conclusion It has never been more important for fundraisers to deliver an excellent donor experience. Fundraisers must employ coaching and facilitation skills to empower supporters to create value. Further research is required to ascertain how managers of fundraising can deliver service encounters and tangible resources that best facilitate the creation of value for the donor.

\section{Parallel Session 3: Symptom Management and Treatment}

\section{0-9 THE DEVELOPMENT OF A CENTRALISED METASTATIC SPINAL CORD COMPRESSION COORDINATOR SERVICE}

Lena Richards, Vivek Misra, Claire Shanahan. The Christie NHS Foundation Trust, Manchester, UK

\subsection{6/bmjspcare-2019-HUKNC.9}

Background MSCC is estimated to occur in 5-10\% of cancer patients. Prompt diagnosis and treatment is essential to prevent paralysis. Failure to recognise early signs can have devastating implications, including the financial burden of care for patients who become bedbound and with earlier than expected death. 